\title{
Escuta de crianças vítimas de abuso sexual no âmbito jurídico: uma revisão crítica da literatura
}

\author{
Janaina Petry Froner \\ Vera Regina Röhnelt Ramires \\ Universidade do Vale do Rio dos Sinos, São Leopoldo-RS, Brasil
}

\begin{abstract}
Resumo: O artigo apresenta uma revisão da literatura que aborda o tema do atendimento de crianças vítimas de abuso sexual intrafamiliar no âmbito do Judiciário. São discutidas as diversas metodologias de escuta da criança, realizadas por profissionais da área da saúde e pelos operadores do Direito. As exigências e os ritos do Sistema Judiciário, assim como as necessidades e demandas das crianças que sofreram abuso sexual também são discutidas, com base na literatura nacional e internacional disponível. Foram abordadas a complexidade e a peculiaridade desse atendimento, a importância e a necessidade de um trabalho interdisciplinar.
\end{abstract}

Palavras-chave: Maus-tratos sexuais infantis. Poder Judiciário. Pesquisa interdisciplinar.

\section{Listening children victims of sexual abuse in the juridical scope: a critical revision of the literature}

\begin{abstract}
The article presents a literature revision about the children victims of sexual abuse assistance in the Judiciary scope. Several methodologies of listening children are argued, accomplished by professionals of the health area and by the judiciary operators. The demands and the legal system rites, as well as the needs and children's demands who suffered sexual abuse are also argued, with base in the national and international available literature. The complexity and the peculiarity of this assistance, and the importance and need of an interdisciplinar work were boarded.
\end{abstract}

Keywords: Child abuse, sexual. Judicial Power. Interdisciplinary research.

\section{Los niños víctimas de abuso sexual en el plano jurídico: una revisión crítica de la literatura}

Resumen: El artículo presenta una revisión de la literatura que se ocupa de la atención de los niños víctimas de abuso sexual en el plano judicial. Se examinaran los distintos métodos de escuchar al niño, llevada a cabo por profesionales de la salud y los operadores de la ley. Los requisitos y los ritos del poder judicial, y si realizo una discusión de las necesidades y demandas de los niños que sufrieron abuso sexual, con base en la literatura nacional e internacional disponible. La complejidad y la peculiaridad de la atención de estos niños, así como si abordaron la importancia y la necesidad del trabajo interdisciplinario.

Palabras clave: Abuso sexual infantil. Poder Judicial. Investigación interdisciplinaria. 
O objetivo desse artigo é apresentar uma revisão da literatura que aborda o tema do atendimento de crianças vítimas de abuso sexual intrafamiliar no âmbito do Judiciário. A escuta da criança vítima de abuso sexual nos processos judiciais dos quais ela é peça fundamental é um tema delicado, complexo, que demanda estudos que venham a colaborar para o seu aprimoramento. Alguns trabalhos teóricos trazem contribuições a respeito da necessidade de tratamento diferenciado em face das demandas dessas crianças e suas famílias (Azambuja, 2006; Brito, Ayres, \& Amendola, 2006). Outros estudos enfatizam a importância da estrutura da entrevista com a criança, para alcançar os indícios do abuso, porém minimizando danos secundários a essas crianças (Daltoé-Cezar, 2007; Dobke, 2001; Juárez-López, 2006; Estado de Michigan, 1998/2003).

Entre os estudos dedicados ao tema da escuta das crianças no âmbito do Judiciário, há um predomínio de revisões bibliográficas (Azambuja, 2006; Azevedo, 2001; Brito e cols., 2006; Ferreira, 2007; Rovinski, 2004). A metodologia quantitativa aparece em pesquisas que realizaram um mapeamento dos serviços de atendimento às vítimas ou de fatores de risco presentes no contexto dessas crianças, através de análises documentais (Habigzang, Azevedo, Koller, \& Machado, 2006; Habigzang, Koller, Azevedo, \& Machado, 2005). Os estudos que focalizaram as entrevistas de averiguação da credibilidade dos relatos da criança, em geral, utilizaram questionários semi-estruturados ou estruturados para coleta dos dados e análise de conteúdo ou de discurso para sua análise (Juárez-López, 2006; Lamb e cols., 2003; Rogers \& Brodie, 2004; Estado de Michigan, 1998/ 2003). Alguns estudos sobre o atendimento da criança vítima de abuso sexual utilizaram delineamentos exploratórios ou descritivos (Daltoé-Cezar, 2007; Dobke, 2001). As modalidades de estudos de caso, relatos de experiência ou pesquisa-intervenção também têm sido utilizadas (Heiman \& Ettin, 2001; Junqueira, 2002; Ramires \& Froner, 2008).

A revisão de literatura foi realizada com base em consulta às seguintes bases de dados: LILACS, SciELO, PsycINFO e PubMed. Os descritores utilizados foram "abuso sexual", "escuta de crianças", “escuta e judiciário", "atendimento de crianças e ju- diciário", "depoimento", "inquirição" e "oitiva da criança". O período estabelecido para a revisão foi os últimos 15 anos, tendo sido revisadas publicações em língua inglesa, espanhola e portuguesa.

A seguir, apresenta-se brevemente o conceito e as implicações do abuso sexual intrafamiliar e alguns dados estatísticos sobre o mesmo. Na sequiência, discute-se o atendimento prestado à criança vítima de abuso sexual, com base na literatura revisada.

\section{O abuso sexual e suas implicações}

No Brasil, o abuso sexual como atitude violenta contra a criança e o adolescente ganhou maior visibilidade e importância nas últimas décadas, com a implantação do Estatuto da Criança e do Adolescente (ECA), em 1990, a partir do qual crianças e adolescentes passaram a ser considerados sujeitos em condições peculiares de desenvolvimento, bem como sujeitos de direto, com prioridade absoluta de atendimento (Azambuja, 2005; Azambuja, 2004, 2006; Brito e cols., 2006; Cesca, 2004; Daltoé-Cezar, 2007; Dias, 2007; Habigzang e cols., 2005, 2006). Porém, os abusos sexuais sempre foram praticados, em todos os tempos da nossa história, em todas as classes sociais (Aded, Dalcin, Moraes, \& Cavalcanti, 2006; Azambuja, 2004; Daltoé-Cezar, 2007). Nos últimos anos, o abuso sexual vem sendo reconhecido como um dos mais graves problemas de saúde pública (Habigzang e cols., 2005, 2006; Pfefferbaum \& Allen, 1998).

O número de casos envolvendo crianças e adolescentes em atividades sexuais de adultos é significativo (Aded e cols., 2006). Dos casos notificados nos três primeiros meses de cada ano, baseando-se em dados de 70 municípios de 14 estados brasileiros, mais o Distrito Federal, entre as crianças e adolescentes que sofreram violência doméstica, a violência sexual esteve presente em 13,2\% em 2006 e 9,0\% dos casos em 2007 (Universidade de São Paulo, 2007).

Contudo, esse número não apresenta a realidade do fenômeno. De acordo com Dias (2007), apenas 10 a $15 \%$ dos casos de abuso sexual são denunciados. Estudos confirmam a dinâmica da "síndrome do silêncio" nos casos de abuso sexual intrafamiliar, como se houvesse um "muro de silêncio", também entre os vizinhos e profissionais que 
atendem essa população (Azambuja, 2004; Braun, 2002; Daltoé-Cezar, 2007; Dobke, 2001; Pfeiffer \& Salvagni, 2005). Embora as crianças sejam as vítimas preferidas dos abusadores sexuais, muitos casos só são descobertos ou desvendados anos mais tarde, na adolescência ou na vida adulta (Braun, 2002; Dobke, 2001; Habigzang e cols., 2005; Sanderson, 2005).

Watson (1994), assim como Rodrigues, Brino e Williams (2006), sugerem que não há uma definição única do abuso sexual de crianças. Esses autores salientam três pontos que servem para distinguir atos abusivos dos não-abusivos: (1) o abusador tem um poder hierárquico superior, exercendo controle sobre a vítima que não compreende o que se passa; (2) o agressor deve possuir uma diferença na idade cronológica ou avanço no desenvolvimento socialcognitivo; (3) o agressor busca ou obtém gratificação e satisfação, sendo que um possível prazer da vítima é acidental ou de interesse de quem abusa. Já Glaser (1991) define o abuso sexual infantil como o envolvimento de crianças e adolescentes em atividades sexuais que não compreendem em sua totalidade, para as quais não estão aptos a concordarem e que violam as regras sociais e familiares de nossa cultura. Uma das formas em que o abuso sexual se apresenta pode ser entendida como incesto, na qual geralmente ocorre uma cronificação em virtude da ocorrência por um período longo de tempo e do laço de confiança e segredo no seio da família, forma que, para Junqueira (2002), pode ser desestruturante para organização psíquica das crianças envolvidas.

A literatura tem mostrado que o maior número de crianças violentadas sexualmente ocorre dentro da própria casa, perpetrada por algum membro da família, ou outra pessoa que exerça função parental, sem necessariamente haver laços de consangüinidade (Azambuja, 2004; Azambuja, 2005; Barbosa, 2007; Braun, 2002; Rodrigues e cols., 2006; Sanderson, 2005). Em 90\% dos casos notificados, "o autor é um membro da família da vítima, é alguém que ela ama, conhece e respeita" (Dias, 2007, p. 23). Normalmente aquele que exerce a função paterna, como pai, padrasto e/ou avô.

Por ser cometido na clandestinidade e, na maioria das vezes, sem deixar qualquer vestígio físico (Azambuja, 2004; Daltoé-Cezar, 2007; Dobke,
2001; Habigzang e cols., 2005), o abuso sexual intrafamiliar produz uma série de dificuldades no desenvolvimento psicológico, afetivo, cognitivo, intelectual, sexual, físico e/ou neurológico (Braun, 2002; Ghetti, Alexander, \& Goodman, 2002; Rouyer, 1997; Sanderson, 2005). O abuso sexual deixa a criança traumatizada, pois deteriora a capacidade reflexiva e o sentido de self, o que torna o ciclo de desenvolvimento muito perturbado (Thouvenin, 1997). Além disso, os inúmeros danos possíveis na área da saúde mental podem persistir na vida adulta (Aded e cols., 2006; Pfeiffer \& Salvagni, 2005). Crianças abusadas podem se tornar adultos abusivos ou vitimizados, conforme Aded e cols. (2006), reproduzindo relacionamentos disfuncionais com suas próprias famílias, apresentando transtornos dissociativos e de personalidade borderline, dentre outros transtornos psiquiátricos e/ou emocionais (Habigzang e cols., 2005; Rodrigues e cols., 2006). Em contrapartida, Silva, Elsen e Lacharité (2003) apresentam dados que mostram a possibilidade dessas pessoas responderem de forma positiva as situações adversas mesmo quando estas representam risco para sua saúde ou seu desenvolvimento, desde que tenham laços afetivos fortalecidos dentro da família (com pelo menos um cuidador) e suporte emocional na rede de apoio (como professores, amigos e outros profissionais).

Diante da complexidade e das particularidades que envolvem a dinâmica do abuso sexual intrafamiliar, e das conseqüências para a saúde mental da criança, compreende-se a dificuldade que ela enfrenta para expressar ou revelar a situação do abuso no contexto familiar. Além disso, e para que seja garantida sua proteção integral, a revelação do abuso poderá implicar em algum processo judicial, fazendo com que a criança precise envolver-se com o Sistema de Justiça. Reviver os fatos através da revelação gera sentimentos de culpa, vergonha, medo, além de sentimentos ambivalentes em relação ao agressor, possibilidade de desintegração da família e/ou institucionalização da criança (Azambuja, 2006; Azevedo, 2001; Ferreira \& Schramm, 2000).

Confrontar-se com uma realidade da qual não gostaria de tomar conhecimento pode produzir outros efeitos graves no psiquismo da criança e de sua família (Azambuja, 2006; Azevedo, 2001; Daltoé-Cezar, 2007; 
Dobke, 2001). Daí a importância de se refletir a respeito da forma como esta criança será acolhida pelo Judiciário, como será realizado o seu atendimento, a sua escuta nesse contexto, o que nos conduz a considerar as necessidades das crianças e as exigências e os ritos do Judiciário.

\section{As necessidades e demandas do Judiciário}

O objetivo do Sistema Judiciário é buscar a justiça social e garantir o direito dos cidadãos. Na situação da criança sexualmente abusada, operadores do Direito necessitam aplicar a lei maior (Constituição Federal) assim como o Estatuto da Criança e do Adolescente para garantir a sua proteção integral e responsabilizar o agressor. Para alcançar esse propósito, a escuta das crianças envolvidas no abuso sexual vem sendo defendida como um direito fundamental em todo o mundo. Diante da suspeita de abuso e da falta de provas concretas no seu corpo, além de toda a dinâmica que envolve o fenômeno do abuso sexual intrafamiliar, as declarações das crianças podem se tornar referência importante e às vezes decisiva na formalização de uma prova judicial. (Brito e cols., 2006; Daltoé-Cezar, 2007; Davies, Wescott, \& Horan, 2000; Juárez-López, 2006; Koshima, 2003; Morales \& Schramm, 2002).

Porém, a constituição dessa prova através da inquirição da criança nem sempre acontece. $\mathrm{O}$ impacto da violência sofrida, assim como a demora dos processos até que a criança seja designada para sua oitiva, muitas vezes, pode gerar maior ansiedade, o que Colacique (2006) chamou de sofrimento acumulativo diante das tramitações jurídicas. A dor do trauma, assim como o medo de represálias pode comprometer a precisão em relação à descrição do local, tempo, recorrência e outros detalhes específicos do abuso, o que para os magistrados significa uma "não-prova" (Azambuja, 2006; Dobke, 2001). De acordo com as normas processuais, a escuta da criança vítima de abuso sexual intrafamiliar é realizada pelo juiz de Direito, o qual faz perguntas diretas, coletando informações sobre o abuso em uma sala de audiências formal. Nessas ocasiões de aferição de provas, a palavra da criança é muitas vezes confrontada com a versão do agressor, que pode ser ouvido ou questionado na presença da criança, repassando a responsabilidade total à vítima, considerando assim seu relato inválido, desacreditado, infantil e fantasioso (Azambuja, 2005; Azambuja, 2006; Dobke, 2001).

Esse procedimento para a escuta da criança faz com que ela se sinta culpada indevidamente, o que gera riscos para seu desenvolvimento e para a validade do seu testemunho (Daltoé-Cezar, 2007; Dobke, 2001; Sanderson, 2005; Thouvenin, 1997).É comum, nos casos de crianças e de adolescentes envolvidos no incesto, que a família projete a culpa das circunstâncias sobre eles. Nesse sentido, podem recorrer à retratação, negação ou dissociação, por não suportarem tamanha pressão, o que é compreendido como prova do caráter infundado de acusação pelos magistrados (Azevedo, 2001; Dobke, 2001).

Ao tornar a sua palavra pública, a criança expõe todo o seu íntimo, de um total silêncio e segredo, ela passa a ser vulnerável, para cumprir com procedimentos jurídicos (Azambuja, 2006; Azevedo, 2001; Brito e cols., 2006; Ferreira, 2007; Koshima, 2003; Thouvenin, 1997). Portanto, pode se dizer que o trauma do abuso sexual tem consequiências que vão além daquelas causadas pelo fato em si, apresentando efeitos do processo legal e seus desdobramentos (Araújo, 2002; Azambuja, 2004, 2006; Azevedo, 2001; Ghetti e cols., 2002; Ward, 2003).

A forma tradicional de realizar a escuta da criança no âmbito do Judiciário em nosso país data de décadas anteriores à Constituição de 1988. Não há nada de novo nessa escuta que considere as condições especiais da criança - idade, maturidade e sofrimento emocional proveniente da agressão sofrida (Azambuja, 2006; Benfica \& Souza, 2002; DaltoéCezar, 2007; Dobke, 2001). As crianças abusadas sexualmente costumam ser escutadas como qualquer pessoa adulta que tenha se envolvido em qualquer situação ilícita, conforme Azambuja (2006). Para a proteção integral da criança é necessário que tais instituições realizem uma revisão, análise e reestruturação das práticas utilizadas na vigência do comando constitucional anterior (Azambuja, 2006; Brito e cols., 2006; Dias, 2007; Sanderson, 2005).

Diante das dificuldades e divergências encontradas na oitiva das crianças, alguns países modificaram sua legislação em relação a essa questão, com objetivo de maior proteção à criança durante a constituição da prova. A Argentina e a Espanha, por 
exemplo, proíbem a escuta direta da criança pelos juízes de Direito e pelas partes. A África do Sul possui um sistema de intermediação por profissionais da área da saúde, que tentam reduzir o trauma e o abuso secundário durante a coleta do depoimento (JuárezLópez, 2006; Yiming \& Fung, 2003). Já a França torna preferencial esse tipo de escuta, enquanto que o Brasil possui um Projeto de Lei 7.524, de 2006, que propõe como preferencial a inquirição em local apropriado para o acolhimento da criança, intermediada por profissional designado pela autoridade judiciária e registrada por meio audiovisual, para fazer parte integrante do processo (Daltoé-Cezar, 2007).

Thèry (1992), considera que ao exercer o direito de testemunhar (que pressupõe responsabilidade civil e capacidade jurídica), mesmo com cuidados especiais na sua escuta, a criança perde o direito à infância, exercendo funções que são de responsabilidade dos adultos. A autora sugere uma maior participação da família nos processos, para zelar pelos direitos da criança ou do adolescente em condições peculiares de desenvolvimento.

Na mesma direção, algumas autoras defendem a idéia de que a criança em sofrimento não precisa ser inquirida em juízo (Azambuja, 2006; Ferreira, 2007). Azambuja refere que não existe nenhum parágrafo no Princípio Constitucional apontando que ela necessite ser ouvida. As autoras mencionam que a escuta no âmbito do Judiciário não respeita integralmente a criança, pois há a violência decorrente da exigência de produzir a prova da materialidade do abuso sofrido através da solicitação de informações detalhadas, desconsiderando o estágio de maturidade e desenvolvimento em que ela se encontra. Por outro lado, compreende-se que ao não abrir espaço para a criança falar sobre o abuso no Sistema Judiciário, na tentativa de protegê-la, corre-se o risco de rejeitar sua experiência e a própria criança, além de fortalecer a síndrome do segredo, pois segundo os autores, o silêncio é o que mantêm e obriga a criança a submeter-se às humilhações (Daltoé-Cezar, 2007; Dobke, 2001; Koshima, 2003).

Uma outra opção utilizada e defendida por algumas estudiosas na área dos direitos da infância e do adolescente é a avaliação técnica realizada pelo profissional da área da saúde (Azambuja, 2006; Ferreira, 2007). A perícia serve para auxiliar o juiz de Direito em algum impasse ou conflito que ele não possua competência técnica para compreender ou decifrar (Herman, 2005; Rovinski, 2004; Shine, 2005). Diferentemente de um depoimento ou inquirição, é uma forma de escutar as crianças no âmbito do Judiciário sem a obrigatoriedade de aferição de provas. Pode ser realizada pelo médico, pelo psicólogo ou pelo assistente social, legalmente matriculado em seu órgão de classe, que seja especialista no assunto em questão (Ramires, 2006; Rovinski, 2004; Viaux, 1997). Constata-se, pois, que começam a surgir estudos que apontam para a importância de uma postura diferenciada do profissional que realiza a escuta, priorizando a proteção da criança e as suas necessidades.

\section{As necessidades da criança e as possibilidades de sua escuta}

As condições particulares de desenvolvimento das crianças, somadas à situação de trauma pelo abuso sexual sofrido, exigem competências múltiplas dos profissionais que realizam o seu atendimento no cenário do Judiciário. Os estudos revisados salientam a necessidade de capacitação, treinamento técnico e preparação emocional constante desses profissionais para intervenções adequadas com as crianças (Azambuja, 2005; Azambuja, 2006; Azevedo, 2001; Habigzang e cols., 2006). Alguns estudiosos pesquisaram e comprovaram que os operadores do Direito apresentavam dificuldade na realização do ato processual de inquirir a criança sexualmente abusada e em aderir às práticas de entrevistas recomendadas para evitar maior sofrimento à vítima (Dobke, 2001; Lamb e cols., 2003; Pfeiffer \& Salvagni, 2005). Esses autores concluíram que indiferente da área do profissional que realiza a escuta, há a necessidade de ele ter uma visão psicológica, o que implica em conhecimento teórico e prático na área da saúde mental, além de empatia e sensibilidade para lidar com as crianças em sofrimento e com o fenômeno do abuso. Ainda, há a necessidade de possuir conhecimento da legislação específica para realizar a escuta das crianças na esfera jurídica. 
O profissional treinado pode analisar o relato da criança e a partir dele encontrar indícios do abuso. Segundo alguns autores, o profissional da área da saúde mental é um agente facilitador da fala e das emoções da criança (Azambuja, 2006; Benfica \& Souza, 2002). A fala livre e/ou perguntas abertas, sem pressão e sem sugestionabilidade, com linguagem simples, possibilita à criança dar uma resposta com maior conteúdo informativo (Davies e cols., 2000; Dobke, 2001; Juárez-López, 2006; Rovinski, 2004). Lamb e cols. (2003) desenvolveram entrevistas programadas com estímulos livres, para que os entrevistadores conseguissem escutar as memórias espontâneas das crianças entre quatro e oito anos, maltratadas sexualmente. Porém, faz-se necessário levar em consideração que as crianças com menor maturidade ou menor idade possuem menor capacidade de memorizar e de recordar dados detalhados (Dobke, 2001; Juárez-López, 2006; Estado de Michigan, 1998/2003).

Através de jogos, bonecos anatômicos, instrumentos projetivos, desenhos e outros materiais gráficos, consegue-se superar as habilidades verbais limitadas das crianças, assim como auxiliar na sua avaliação (Pfeiffer \& Salvagni, 2005). As atividades lúdicas facilitam tanto o vínculo como a escuta da criança, pois ela descreve, até mesmo em detalhes, todo o seu sofrimento através do jogo simbólico (Pfeiffer \& Salvagni, 2005; Ramires \& Froner, 2008). Por isso, Junqueira (2002) reforça a necessidade do brincar livre como uma linguagem importante e usual para expressão da criança, que deve ser valorizada na sua escuta para superar e elaborar a situação traumática. Dessa forma, a experiência da criança aparece com maior facilidade, sem indução alguma.

O profissional deve levar em consideração a experiência vivenciada pela criança e a tensão psíquica que demanda dela para promover intervenções que possibilitem uma elaboração psíquica do seu estado emocional (Azevedo, 2001; Colacique, 2006; Ramires \& Froner, 2008). O profissional deve proteger a criança antes, durante e após o processo judicial, refere Saywitz (2002). A autora salienta ainda a necessidade de preparar cuidadosamente a criança para a sua escuta, ou seja, situá-la, amenizando seus medos e crenças, assim como se deve eliminar a desorientação e confusão que o Sistema Legal pode nela produzir. Na mesma direção, Junqueira (2002) alerta para a importância de orientar a criança sobre os procedimentos que ela precisa enfrentar e deixar claro que, para garantia de sua proteção integral, não pode haver contrato de sigilo absoluto dos atendimentos.

$\mathrm{O}$ acolhimento da criança e da sua dor, em um ambiente tranqüilo e lúdico, é a base para um bom resultado (Daltoé-Cezar, 2007; Pfeiffer \& Salvagni, 2005). Para isso, os autores são unânimes em ressaltar que a atitude do profissional frente aos fatos apresentados não deve ser julgadora ou punitiva, proporcionando uma relação de confiança (vínculo) que ajudará no acompanhamento subsequiente (Dobke, 2001; Ferreira, 2005; Junqueira, 2002).

Depreende-se que para que a escuta seja em benefício da criança, ela precisa sentir-se respeitada incondicionalmente. Sua forma de se expressar e até mesmo o seu silêncio deve ser compreendido (Barbosa, 2007; Crivillé, 1997; Heiman \& Ettin, 2001; Hutchby, 2005; Pfeiffer \& Salvagni, 2005). De San Lazaro (1995) sugere que quando a criança não deseja falar sobre o abuso, possa indicar um adulto de sua confiança, que tenha um vínculo positivo com ela, para falar sobre o fato ocorrido.

De forma geral, os demais profissionais que escutam as crianças abusadas sexualmente devem priorizar o seu acolhimento. O médico, por exemplo, deve ouvila, além de verificar sua condição física e conduzir os procedimentos necessários com infinito tato para não agravar seu sofrimento (De San Lazaro, 1995; Pfeiffer \& Salvagni, 2005; Tomkiewicz, 1997). O médico e o enfermeiro podem contribuir com uma escuta que vá além dos exames e tratamentos clínicos tradicionais da área, trabalhando preventivamente, especialmente com os cuidadores da criança (Ferreira, 2005).

Diversos autores consideram que as pessoas geralmente falam a verdade sobre suas experiências sexuais e que isso é especialmente válido para crianças e adolescentes vítimas de abuso sexual intrafamiliar (Braun, 2002; Crivillé, 1997; Dobke, 2001; Sanderson, 2005). Contudo, é necessário distinguir quando a criança pode estar apresentando "falsas memórias", uma psicopatologia caracterizada pela crença absoluta em pseudomemórias de abuso sexual (Pinchaski, Víquez, \& Zeledón, 2004; Stein \& Neufeld, 2001). Uma forma de implantação de falsa memória na criança é a conseqüência do seu 
envolvimento na Síndrome de Alienação Parental (SAP), um processo que pode ocorrer após a separação dos pais, quando um dos genitores, geralmente a mãe, influencia a criança para que odeie o pai, sem qualquer justificativa, com o objetivo de impedir ou romper a relação dele com o filho. Esse dispositivo é utilizado como instrumento de raiva da mãe, direcionada ao ex-parceiro (Gardner, 2002). Uma das consequiências dessa síndrome pode ser uma falsa denúncia de abuso sexual, gerando seqüelas nefastas na criança (Junqueira, 2002; Rovinski, 2004; Trindade, 2007).

Para garantir a proteção da criança, sendo essa uma de suas necessidades, a revelação ou confirmação do abuso também é considerada importante. Algumas técnicas têm sido utilizadas no campo do Judiciário, especialmente no exterior, para minimizar danos à população infantil. A literatura evidencia que as técnicas de entrevista forense apresentam normalmente uma estrutura baseada na Avaliação de Validade do Relato (AVR). Originada na Alemanha em 1954, continua sendo uma forma importante em todo o mundo para medir a veracidade do relato da criança, embora não seja padronizada (Rovinski, 2004). Consiste em uma entrevista estruturada para exploração do evento traumático, com o maior número de informações possíveis, transcrita em áudio para posterior análise do conteúdo do relato, através da Análise de Conteúdo Baseada em Critério (ACBC) (Juaréz-Lopes, 2006; Rogers \& Brodie, 2004; Rovinski, 2004).

O ACBC é um protocolo com 19 critérios (entre eles: coerência e lógica da declaração, informações prestadas de forma cronológica, verbalização espontânea, detalhes em quantidade suficiente, lembrança de conversações, dentre outros) que devem ser pontuados de zero a três, conforme presença no relato. Após essa etapa, faz-se necessário averiguar a validade da entrevista de acordo com os critérios levantados na etapa anterior (Rovinski, 2004). Contudo, Rogers e Brodie (2004) testaram esse protocolo e consideraram particularmente difícil avaliar a veracidade do conteúdo através de um instrumento. Verificaram que, à medida que a criança está familiarizada com um fato alegado, seu relato está propenso a ter um conteúdo que produz um escore alto no instrumento, indicando que o evento ocorreu, tenha ele acontecido ou não.
Mesmo assim, outros pesquisadores do testemunho da criança no Sistema Judiciário desenvolveram protocolos de entrevista a partir do AVR e ACBC (Estado de Michigan, 1998/2003; Juárez-López, 2006; Poole \& Lamb, 1998; Yuille, Hunter, Joffe, \& Zaparniuk, 1993). Esses autores afirmam que buscam uma escuta de qualidade, ou seja, evitando perguntas sugestivas ou diretivas durante o método de interrogatório, dando maior credibilidade aos processos jurídicos e para responsabilização do agressor. Buscam confirmar com algum grau de certeza a identificação do abuso e do perpetrador, dentro de um clima de cordialidade, sensibilidade e imparcialidade, facilitado pela entrevista realizada em etapas, evitando deixar alegações sujeitas a múltiplas interpretações e reduzindo a possibilidade de novos traumas para a criança.

Essas técnicas foram desenvolvidas e aprimoradas pelos operadores do Direito e por profissionais da área da saúde em decorrência da preocupação com a exposição da criança que precisa dar o seu testemunho em juízo. Essas entrevistas ampliam a qualidade do conteúdo do depoimento infantil, evitando novas versões de oitivas nesse contexto.

Tem sido sugerido que a entrevista com a criança seja sempre registrada audiovisualmente por dois motivos principais: (1) o entrevistador pode incrementar sua precisão e competência sobre a evolução e o conteúdo da entrevista; (2) a criança deixa de ser exposta a novas entrevistas em caso de dúvidas, pois o documento gravado fica anexado ao processo judicial (Daltoé-Cezar, 2007; 2006; Rovinski, 2004). Já o Protocolo de Entrevista Forense de Michigan-FIA (Estado de Michigan, 1998/2003) propõe que a criança seja escutada por mais de um profissional através da sala de espelhos.

Juárez-López (2006) aperfeiçoou o protocolo de investigação de Lamb, Sternberg, Esplin, e Orbach (2000). Esses autores desenvolveram no Centro Nacional de Saúde Infantil e Desenvolvimento Humano (NICHD), um protocolo de investigação para vítimas de abuso sexual com os mesmos princípios de averiguar a suspeita do abuso. Após aplicação prática em entrevistas forenses durante mais de três anos, nos Juizados de Girona, na Espanha, Juárez-López desenvolveu o Guia de Entrevista Assistida para Inqui- 
rição do Abuso Sexual Infantil (EASI-5). Uma entrevista semi-estruturada com um momento introdutório, de avaliação das condições da criança para relatar fatos ocorridos, fazendo distinções sobre mentira e verdade, fantasia e realidade, voltando-se a assuntos e eventos da vida escolar e familiar. No desenvolvimento da entrevista o profissional da saúde pode avaliar as áreas da competência infantil (memória, personalidade, questões sociais, nível de conhecimento corporal/sexual, dentre outras). Essa proposta é compartilhada também por Rovinski (2004) e pelos autores do Protocolo de Entrevista Forense de Michigan-FIA (Estado de Michigan, 1998/2003).

Daltoé-Cezar (2007), juntamente com um grupo de profissionais de distintas áreas do conhecimento, tomaram como base os achados científicos de Dobke (2001) e de projetos realizados no exterior para iniciarem no Brasil, na cidade de Porto Alegre-RS, em 2003, o Projeto Depoimento Sem Dano. Essa proposta foi fundamentada por um estudo teórico-prático, que investigou uma amostra de 101 processos e as respectivas inquirições realizadas pelo profissional da área da saúde, entre maio de 2003 e dezembro de 2005. Foi constatado que a operacionalização dessa modalidade de escuta, assim como sua metodologia, que possui como objetivo a materialização da prova com o menor sofrimento possível para a criança, são positivos em relação ao ato processual de inquirição da vítima (depoimento) tradicional proposto pelo Código de Processo Penal. Porém, o autor não descarta a possibilidade de aperfeiçoamento em algumas questões metodológicas.

Nesse sentido, reforça-se a importância de adaptações no Sistema Judiciário para a realização da escuta da criança vítima de abuso sexual intrafamiliar, levando em consideração as necessidades da criança, decorrentes especialmente do seu grau de maturidade e do sofrimento significativo proveniente do trauma experimentado.

\section{A necessidade do trabalho interdisciplinar}

A partir do exposto, percebe-se o quanto é complexo, difícil e peculiar escutar as crianças no âmbito do Judiciário, conseguindo protegê-las integralmente e ao mesmo tempo respeitando-as em relação aos aspectos relativos a uma suposta experiência trau- mática (Azevedo, 2001; Junqueira, 2002). Isto exige um trabalho de equipe efetivo, que vá além da multidisciplinaridade. $\mathrm{O}$ atendimento da criança sexualmente abusada exige um trabalho interdisciplinar, com capacitação profissional e preparação pessoal e emocional continuadas, ampliando a compreensão dos casos e possibilitando intervenções adequadas (Aded e cols., 2006; Azambuja, 2005; Azevedo, 2001; Cesca, 2004; Deblinger, Lippmann, Stauffer, \& Finkel, 1994; Heiman \& Ettin, 2001; Junqueira, 2002; Koshima, 2003). Um empecilho para o desenvolvimento da abordagem interdisciplinar é que, na prática, há falha na comunicação entre os serviços que compõem a rede de proteção, dificultando o trabalho já existente (Habigzang e cols., 2006).

A formação pessoal e profissional para o trabalho com o abuso sexual intrafamiliar também é fundamental (Azambuja, 2005). Alonso-Quecuty (1999) compreende que cada pessoa tem teorias implícitas ou concepções a respeito de determinadas situações. Cada indivíduo elabora suas concepções com base em sua história pessoal e experiências, vivenciadas no grupo cultural onde está inserido.

Sendo assim, compreende-se que profissionais da área da saúde e operadores do Direito possuem formações distintas que lhes fazem pensar, sentir e atuar diferentemente ao escutar uma criança. Contudo, essa escuta operacionalizada por distintas áreas do conhecimento deve ocorrer em sintonia, de forma articulada, em um contexto no qual estejam claramente definidos e respeitados os limites de cada uma (Aded e cols., 2006; Azambuja, 2005; Brito e cols., 2006; Habigzang e cols., 2006; Pfeiffer \& Salvagni, 2005; Ramires \& Rodrigues, 2004).

O profissional da saúde é um parceiro importante na escuta da criança no contexto do Judiciário. Durante todo o processo em que a criança estiver envolvida com a Justiça, ele poderá avaliar suas condições, aliviar angústias e contribuir para não causar outras, principalmente através de uma postura diferenciada (Azambuja, 2005, Azambuja, 2006; Benfica \& Souza, 2002; Daltoé-Cezar, 2007; Ferreira, 2005; Junqueira, 2002). Na condição de perito, esse profissional possui a vantagem de dispor de um tempo maior para formação de um vínculo de confiança com a criança e para respeitar o seu tempo, sem correr o risco de pressioná-la e/ou de rejeitar sua experiência traumática (Ramires, 2006). 
Com formação adequada para isso, poderá fazer uma avaliação mais aprofundada, com a possibilidade de compreender conteúdos latentes da dinâmica do caso, traduzindo para o juiz de Direito o que for do melhor interesse da criança, garantindo sua proteção integral (Azambuja, 2006; Ferreira, 2007; Junqueira, 2002). Os subsídios oferecidos por esse tipo de avaliação poderão ser um diferencial no momento em que o magistrado necessitar concluir o julgamento do caso, podendo chegar à responsabilização do agressor sexual (Azevedo, 2001; Cesca, 2004).

É importante registrar que se for do interesse da criança, ou se houver necessidade ou desejo de ela dar o seu depoimento em juízo, o que é diferente da avaliação ou perícia na área da saúde, ou ainda se o juiz de Direito entender que seja imprescindível a sua oitiva no espaço do Judiciário, que essa possa ser realizada em Juizados especializados, com aperfeiçoamento e distinção da inquirição da criança vítima de abuso sexual (Brito e cols., 2006; Dias, 2007). Pode-se dizer que os procedimentos desenvolvidos na última década para a escuta da criança no âmbito do Judiciário são visivelmente mais adequados ao universo infantil, apresentando um acolhimento mais humanizado, se comparados às tradicionais audiências judiciais (Daltoé-Cezar, 2007; Estado de Michigan, , 1998/2003; Juárez-López, 2006; Lamb e cols., 2000).

Somente através de uma escuta sensível e empática alcança-se o conhecimento da experiência da criança. Através de um trabalho interdisciplinar, torna-se possível não somente a proteção dos direitos da criança, mas também a devida atenção ao seu estado subjetivo diante da experiência traumática do abuso sexual intrafamiliar.

\section{Referências}

Aded, N. L. O., Dalcin, B. L. G. S., Moraes, T. M., \& Cavalcanti, M. T. (2006). Abuso sexual em crianças e adolescentes: Uma revisão de 100 anos de literatura. Revista de Psiquiatria Clínica, 33, 204-213.

Alonso-Quecuty, M. L. (1999). Evaluación de la credibilidad de las declaraciones de menores víctimas de delitos contra la liberdad sexual. Papeles del Psicólogo, 73, 36-40.
Araújo, M. F. (2002). Violência e abuso sexual na família. Psicologia em Estudo, 7(2), 3-11.

Azambuja, M. P. R. (2005). Violência doméstica: Reflexões sobre o agir profissional. Psicologia: Ciência e Profissão, 25, 4-13.

Azambuja, M. R. F. (2004). Violência sexual intrafamiliar: É possível proteger a criança? Porto Alegre: Livraria do Advogado.

Azambuja, M. R. F. (2006). Violência sexual intrafamiliar: Interfaces com a convivência familiar, a oitiva da criança e a prova da materialidade. Revista dos Tribunais, 95(852), 425-446.

Azevedo, E. C. (2001). Atendimento psicanalítico a crianças e adolescentes vítimas de abuso sexual. Psicologia: Ciência e Profissão, 21, 66-77.

Barbosa, G. F. (2007). Segredo de família e o tratamento psicanalítico. In M. B. Dias (Org.), Incesto e alienação parental (pp. 93-100). São Paulo: Revista dos Tribunais.

Benfica, F. S., \& Souza, J. R.(2002). A importância da perícia na determinação da materialidade dos crimes sexuais. Revista do Ministério Público do Rio Grande do Sul, 46, 173-186.

Braun, S. (2002). A violência sexual infantil na família. Porto Alegre: AGE.

Brito, L., Ayres, L., \& Amendola, M. (2006). A escuta de crianças no sistema de justiça. Psicologia \& Sociedade, 18(3), 68-73.

Cesca, T. B. (2004). O papel do psicólogo jurídico na violência intrafamiliar: Possíveis articulações. Psicologia \& Sociedade, 16(3), 41-46.

Colacique, M. A. M. (2006). Intervenção psicológica no sofrimento psíquico de criança $e$ adolescente envolvidos com processos em tramitação na justiça. Tese de doutorado nãopublicada, Universidade de São Paulo, São Paulo, SP.

Crivillé, A. (1997). Nem muito, nem pouco, exatamente o necessário: Reflexões a propósito dos profissionais. In M. Gabel (Org.), Crianças vítimas de abuso sexual (pp. 132-143). São Paulo: Summus. 
Daltoé-Cezar, J. A. (2007). Depoimento sem dano: Uma alternativa para inquirir crianças e adolescentes nos processos judiciais. Porto Alegre: Livraria do Advogado.

Davies, G. M., Wescott, H. L., \& Horan, N. (2000). The impact of questioning style on the content of investigative interviews with suspectet child sexual abuse victims. Psychology, Crime and Law, 62, 81-97.

De San Lazaro, C. (1995). Making pediatric assessment in suspected sexual abuse a therapeutic experience. Archives of Disease in Childhood, 73, 174-176.

Deblinger, E., Lippmann, J., Stauffer, L., \& Finkel, M. (1994). Personal versus professional responses to child sexual abuse allegations. Child Abuse and Neglect, 18, 679-682.

Dias, M. B. (2007). Incesto e o mito da família feliz. In M. B. Dias (Org.), Incesto e alienação parental (pp. 17-49). São Paulo: Revista dos Tribunais.

Dobke, V. (2001). Abuso sexual: A inquirição das crianças, uma abordagem interdisciplinar. Porto Alegre: Ricardo Lenz.

Estado de Michigan. Grupo de Trabajo del Gobernador para la Justicia del Menor. Agencia para la Independencia de la Familia. (2003). Protocolo de entrevista forense (E. Cabañas, Trad.). Michigan: Autor. (Original publicado em 1998)

Ferreira, A. L. (2005). Acompanhamento de crianças vítimas de violência: Desafios para o pediatra. Jornal de Pediatria, 81(Supl. 5), 173-180.

Ferreira, A. L., \& Schramm, F. R. (2000). Implicações éticas da violência doméstica contra a criança para profissionais de saúde. Revista de Saúde Pública, 34, 658-665.

Ferreira, M. H. M. (2007). Memórias falsas ou apuração inadequada. In M. B. Dias (Org.), Incesto e alienação parental (pp. 140-145). São Paulo: Revista dos Tribunais.

Gardner, R. A. (2002). Parental alienation syndrome vs. Parental alienation: Which diagnosis should evaluators use in child-custody disputes? American Journal of Family Therapy, 30, 93-115.
Ghetti, S., Alexander, K. W., \& Goodman, G. S. (2002). Legal involvement in child sexual abuse cases: Consequences and interventions. International Journal of Law and Psychiatry, 25, 235-251.

Glaser, D. (1991). Treatment issues in child sexual abuse. British Journal of Psychiatry, 159, 769-782.

Habigzang, L. F., Azevedo, G. A., Koller, S. H., \& Machado, P. X. (2006). Fatores de risco e proteção na rede de atendimento a crianças e adolescentes vítimas de violência sexual. Psicologia: Reflexão e Crítica, 19, 379-386.

Habigzang, L. F., Koller, S. H., Azevedo, G. A., \& Machado, P. X. (2005). Abuso sexual infantil e dinâmica familiar: Aspectos observados em processos jurídicos. Psicologia: Teoria e Pesquisa, 21, 341-348.

Heiman, M. L., \& Ettin, M. F. (2001). Harnessing the power of the group for latency-aged sexual abuse victims. International Journal of Group Psychotherapy, 51, 265-281.

Herman, S. (2005). Improving decision making in forensic child abuse evaluations. Law and Human Behavior, 29, 87-120.

Hutchby, I. (2005). Active listening: Formulations and the elicitacion of feelings-talk in child counseling. Research on Language and Social Interaction, 38, 303-329.

Juárez-López, J. R. (2006). El menor como testigo: Fundamentos y técnicas. In M. A S. Verde \& D. S. Roca, Psicologia criminal (pp. 163-187). Madrid: Pearson Prentice Hall.

Junqueira, M. F. S. (2002). Violência e abuso sexual infantil: Uma proposta clínica. Cadernos de Psicanálise, 18, 209-226.

Koshima, K. (2003). Palavra de criança. In G. Gadelha \& H. Barbosa (Orgs.), Construindo uma história: Tecnologia social de enfrentamento à violência sexual contra crianças e adolescentes (pp. 133-144). Salvador: CEDECA.

Lamb, M. E., Sternberg, K. J., Esplin, P., \& Orbach, I. H. Y. (2000). Assessing the value of structured protocols for forensic interviews of alleged child abuse victims. Child Abuse and Neglect, 24, 733-752. 
Lamb, M. E., Sternberg, K. J., Orbach, Y., Esplin, P., Stewart, H., \& Mitchell, S. (2003). Age differences in young children's responses to open-ended invitations in the course of forensic interviews. Journal of Consulting and Clinical Psychology, 71, 926-934.

Morales, A. E., \& Schramm, F. R. (2002). A moralidade do abuso sexual intrafamiliar em menores. Ciência \& Saúde Coletiva, 7, 265-273.

Pfefferbaum, B., \& Allen J. R. (1998). Stress in children exposed to violence: Reenactment and rage. Journal of the American Academy of Child \& Adolescent Psychiatry, 7, 121-35.

Pfeiffer, L., \& Salvagni, E. P. (2005). Visão atual do abuso sexual na infância e adolescência. Jornal de Pediatria, 81(Supl. 5), 197-204.

Pinchaski, F. S., Víquez, H. E., \& Zeledón, G. C. M. (2004). Memórias impuestas. Medicina Legal de Costa Rica, 21(2), 7-12.

Poole, D. A., \& Lamb, M. E. (1998). Investigative interviews of children: A guide for helping professionals. Washington, DC.: American Psychological Association.

Ramires, V. R. (2006). Elaboração de laudos e outros documentos. In V. R. Ramires \& R. Caminha. Práticas em saúde no âmbito da clínica-escola: $A$ teoria (pp. 271-287). São Paulo: Casa do Psicólogo.

Ramires, V. R., \& Froner, J. P. (2008). A escuta da criança nas situações de abuso sexual intrafamiliar. In S. H. V. Cruz (Org.), A criança fala: A escuta de crianças em pesquisas. São Paulo: Cortez.

Ramires, V. R., \& Rodrigues, M. A. (2004). As transições familiares e o melhor interesse da criança: As perspectivas do Direito e da Psicologia. Estudo e Debate, 11(1), 47-70.

Rodrigues, J. L., Brino, R. F., \& Williams, L. C. A. (2006). Concepções de sexualidade entre adolescentes com e sem histórico de violência sexual. Paidéia (Ribeirão Preto), 16, 229-240.

Rogers, M., \& Brodie, L. (2004). Detecting deception in children: Event familiarity affects criterion-based content analysis ratings. Journal of Applied Psychology, 89, 119-126.
Rouyer, M. (1997). As crianças vítimas, conseqüências a curto e médio prazo. In M. Gabel (Org.), Crianças vítimas de abuso sexual (pp. 62-71). São Paulo: Summus.

Rovinski, S. L. R. (2004). Fundamentos da perícia psicológica forense. São Paulo: Vetor.

Sanderson, C. (2005). Abuso sexual em crianças fortalecendo pais e professores para proteger crianças de abusos sexuais. São Paulo: M. Books do Brasil.

Saywitz, K. J. (2002). Developmental underpinnings of children's testimony. In H. L. Westcott, G. M. Davies \& R. H. C. Bull (Eds.), Children's testimony: A handbook of psychological research and forensic practice (pp. 3-19). London: Wiley.

Shine, S. (Org.). (2005). Avaliação psicológica e lei: Adoção, vitimização, separação conjugal, dano psíquico e outros temas. São Paulo: Casa do Psicólogo.

Silva, M. R. S., Elsen, I., \& Lacharité, C. (2003). Resiliência: Concepções, fatores associados e problemas relativos à construção do conhecimento. Paidéia (Ribeirão Preto), 13, 150-169.

Stein, L. M., \& Neufeld, C. B. (2001). Falsas memórias: Porque lembramos de coisas que não acontecem? Arquivos de Ciências da Saúde da UNIPAR, 5, 179-186.

Thèry, I. (1992). Nouveaux droits de l'enfant, la potion magique? Paris: Esprit.

Thouvenin, C. (1997). A palavra da criança: Do íntimo ao social. Problema do testemunho e da retratação. In M. Gabel (Org.), Crianças vítimas de abuso sexual (pp. 91-102). São Paulo: Summus.

Tomkiewicz, S. (1997). Violências e abusos sexuais em instituições para crianças e adolescentes. In M. Gabel (Org.), Crianças vítimas de abuso sexual (pp. 82-90). São Paulo: Summus.

Trindade, J. (2007). Síndrome de alienação parental (SAP). In M. B. Dias (Org.), Incesto e alienação parental (pp. 101-111). São Paulo: Revista dos Tribunais. 
Universidade de São Paulo. Instituto de Psicologia. Laboratório de Estudos da Criança. (2007). Pesquisando a violência doméstica contra crianças e adolescentes. Recuperado em 02 outubro 2007, de http://www.ip.usp.br/laboratorios/ lacri/index $2 . h t m$.

Viaux, J. L. (1997). A perícia psicológica das crianças vítimas de abusos sexuais. In M. Gabel (Org.), Crianças vítimas de abuso sexual (pp. 121-131). São Paulo: Summus.

Ward, O. A. W. (2003). Trauma por maltrato y revictimización en menores. Medicina Legal de Costa Rica, 20(2), 27-46.

Watson, K. (1994). Substitute care providers: Helping abused and neglected children. Washington, DC: National Center on Child Abuse and Neglect.

Yiming, C., \& Fung, D. (2003). Child sexual abuse in Singapore with special reference to medico-legal implications: A review of 38 cases. Medicine Science and the Law, 43, 260-266.

Yuille, J. C., Hunter, R., Joffe, R., \& Zaparniuk, J. (1993). Interviewing children in sexual abuse cases. In G. S. Goodman \& B. L. Bottoms (Eds.), Child victims, child witnesses: Understanding and improving testimony (pp. 95-115). New York: Guilford Press.

Artigo recebido em 22/10/2007.

Aceito para publicação em 08/07/2008.

Este trabalho é parte da dissertação de Mestrado da primeira autora, orientada pela segunda autora, defendida no Programa de Pós-graduação em Psicologia Clínica da Universidade do Vale do Rio dos Sinos.

Endereço para correspondência:

Janaina Petry Froner. Rua Bento Gonçalves, 1016, sala 603. CEP 95.900-000. Lajeado-RS. E-mail: j.froner@hotmail.com
Janaina Petry Froner é Mestre em Psicologia Clínica pela Universidade do Vale do Rio dos Sinos.

Vera Regina Röhnelt Ramires é Professor Adjunto da Universidade do Vale do Rio dos Sinos. 